\title{
EFFECTS OF TRAINING AND A SEMESTER BREAK ON PHYSICAL FITNESS OF POLICE TRAINEES
}

\author{
Filip Kukić1, Velimir Jeknić2 , Jay Dawes ${ }^{3}$, Robin Orr ${ }^{4}$, \\ Miloš Stojković , and Aleksandar Čvorović \\ ${ }^{1}$ Abu Dhabi Police, Police Sports Education Center, Abu Dhabi, UAE \\ ${ }^{2}$ Abu Dhabi Police College, Department of Sport, Abu Dhabi, UAE \\ ${ }^{3}$ Health Sciences Department, University of Colorado-Colorado Springs, USA \\ ${ }^{4}$ Tactical Research Unit, Bond University, Australia
}

Original scientific paper

DOI: $10.26582 / \mathrm{k} .51 .2 .2$

\begin{abstract}
:
The purpose of this research was to investigate the effects of a physical training program and semester break periods on the chosen physical abilities and basic body composition indicators among police trainees. Body weight (BW), waist circumference (WC), push-ups (PU), sit-ups (SU) and $2.4 \mathrm{~km}$ run (RUN) times of 420 male trainees attending the Abu Dhabi Police College were collected. The testing was conducted by the police education centre during routine testing periods (June, September, December, May) which bracketed the semesters and could be used to investigate the impacts of the physical training program and any potential detraining occurring over the semester break. A repeated measure analysis of variance was performed to identify changes in results across the time periods with a Bonferroni post-hoc adjustment to identify where differences, if any, lay. The level of significance was set at .05 a priori. Following the semester break period from June to September, BW, WC and RUN increased significantly $(p<.01)$, while PU and SU decreased significantly $(\mathrm{p}<.01)$. WC and RUN significantly decreased from September to December and December to May $(\mathrm{p}<.01)$; BW significantly decreased from September to December $(\mathrm{p}<.01)$, but did not change from December to May ( $p=.267)$; PU and SU significantly increased from September to December $(p<.01)$ and December to May ( $\mathrm{p}=.018$ and $\mathrm{p}<.01$, respectively).
\end{abstract}

Key words: law enforcement, cadet, recruit, police academy

\section{Introduction}

Members of the police workforce often, as part of their job duties, must quickly transit from sedentary situations, or situations with a low physical demand, to situations with a high physical demand. These actions, infrequent but usually critical tasks of police officers, are often performed in a hostile and unpredictable environment. In such intense situations, the police officer may be required to perform tasks that include pursuing fleeing subjects, close combat, handcuffing, use of firearms, and riot / crowd control (Lagestad, 2012). Therefore, it is not surprising that in a study by Lagestad (2012) police officers, who had worked for approximately one year, reported that cardio-vascular and muscular endurance were the two physical abilities most required in patrolling duties. Hence, developing physical fitness is an essential component of trainees' initial training.
Physical fitness can be defined as an individual's ability to perform a given physical task (Anderson \& Plecas, 2000; Dawes, Orr, Elder, \& Rockwell, 2014; Dawes, Orr, et al., 2017; Shusko, et al., 2017), warranted by optimally synchronized functioning of the cardio-vascular, respiratory and muscular system (American College of Sports Medicine, 2013). Considering these definitions, physical fitness is essential for police officers if they are to conduct physical work for a prolonged period of time (Anderson, Plecas, \& Segger, 2001; Hauschild, et al., 2017). Unfortunately, the routine physical demands of this job, such as riding in a patrol car and paperwork, are often inadequate for maintaining the necessary physical fitness needed to perform those infrequent, but possibly lifesaving critical functions (Lonsway, 2003). Additionally, low levels of physical activity and lack of exercise have been shown to promote increased body weight 
and body fatty tissue and, consequently, potential health issues (Boyce, Jones, Llyod, \& Boone, 2008; Lagestad \& Van den Tillaar, 2014a, 2014b; Sörensen, Smolander, Louhevaara, Korhonen, \& Oja, 2000). Although police officers in their early career are considered more physically active than the general population, studies indicate that, as the time spent in the police workforce passes, police officers are more prone to become obese with an increased risk of developing diseases related to obesity (Boyce, et al., 2008; Hinton, Stierli, \& Orr, 2017; Orr, Dawes, Pope, \& Terry, 2018; Sörensen, et al., 2000). This may be due, in part, to the social and psychological demands related to police work, such as the pace of daily work, shift work, occupational responsibilities and distressing situations, as well as to the factors such as poor diet and physical inactivity, which can initiate health problems and affect the quality of life among police officers (Hinton, et al., 2017; Lagestad \& Van den Tillaar, 2014a, 2014b; Sörensen, et al., 2000; Violanti, et al., 2009). Thus, consistent monitoring of the status of police officers' body composition and physical fitness throughout their job career should be among the key pillars underpinning successful job performance. In that regard, physical fitness during officers' initial academy training should be developed and promoted, but more importantly, good habits of permanent exercising should be developed through the curriculum.

Numerous studies have found that trainees' fitness can be improved through a good physical training program (Crawley, Sherman, Crawley, \& Cosio-Lima, 2016; Dimitrijević, Koropanovski, Dopsaj, Vučković, \& Janković, 2014; Stojković, Čvorović, Jeknić, \& Kukić, 2017). Stojković et al. (2017) found that two months of training, three times per week for 90 minutes, significantly improved body weight, body fat mass and waist circumference as well as $\mathrm{VO}_{2}$ max in men. Crawley et al. (2016) found that police trainees performing a 16-week exercise program, three 60-minute sessions per week, of aerobic, plyometric, body weight and resistance exercises, significantly improved their upper-body peak power after the first eight weeks of the program and only minimal changes occurred after the second eight weeks. Agility, lower-body peak power, sit-ups, push-ups and a half-mile shuttle run showed significant improvements after the first eight weeks, as well as after 16 weeks of training (Crawley, et al., 2016). A longer, 15-year study of police trainees showed that, although three different training curricula had been applied, they all had a positive effect on police cadets' physical performance (Dimitrijević, et al., 2014). These results suggest that specialized exercise programs, aimed at improving physical fitness, body mass, and body composition, positively impact the health, fitness and performance of police trainees and workers, therefore they should be in the focus of their occupational training. These results also suggest that well-structured programs, even if they vary slightly, can improve fitness of new police trainees.

Considering the mentioned gains in fitness during academy training, previous research also suggests that police officers' fitness deteriorates after exiting the training environment to begin their service (Orr, et al., 2018). For example, Lagestad and Van den Tillaar (2014a) found that after finishing training at their respective police college and starting police work, the physical fitness levels of officers were reduced and their body fat increased after only three years. Additional studies have likewise shown a decrease in physical fitness and increases in body weight, mainly due to the increased fatty tissue mass and infrequent exercise participation over police officers' careers (Boyce, et al., 2008; Gu, et al., 2012; Sörensen, et al., 2000).

While there are several papers that look at the effect of a physical training program on the development of fitness in police academy trainees (Crawley, et al., 2016; Dimitrijević, et al., 2014; Stojković, et al., 2017), there is no known research that investigated both the effects of training and, importantly, the potential detraining on police trainees. This lack of research may be due to many police academy programs being conducted in a single long period, or across two periods without a notable break in between the training. Given the need for police officers to have an optimal level of fitness to perform their key tasks, in addition to the already evidenced deterioration of fitness known to occur in officers, a police academy program that includes an extended period of rest during which a loss of fitness (detraining) may occur, can provide good insights into training and potential detraining factors in this unique population. Therefore, the aims of this research were to investigate both the impact of a physical training program on the basic body composition and physical abilities of police force trainees and to investigate any potential detraining that might occur due to a protracted leave period. It was hypothesized that the physical education curriculum utilized in this study would have a significant positive effect on the parameters of body composition and physical abilities, while a 13-week non-attendance semester break period would have a significant, negative, detraining effect on these same measures.

\section{Methods}

\section{Study design}

This research study employed a longitudinal observational scientific approach with a stratified convenience sample of police college trainees. Anthropometric characteristics and physical performance measurements were collected during regular 
testing procedures for the police trainees of the $\mathrm{Abu}$ Dhabi Police College, with all testing organized by the Police Education Centre. The scheduled time for physical performance testing was between 6 and 9 a.m. Anthropometric measurements were collected first, starting at 6 a.m., followed by the physical fitness measurements. Data acquisition occurred on four separate occasions between June 2016 and the end of May 2017. To investigate the effects of the physical training program on body composition and physical ability, data for the time periods of September-December 2016 (first semester) and December 2016-May 2017 (second semester) were evaluated by assessing associate measures collected at the end of each semester (December 2016 and May 2017). To investigate the effects of the semester break on body composition and physical fitness, data captured just before the summer break in June 2016 and immediately after the break in September 2016 (i.e., approximately 13 weeks or 93 days later) were collected. All data were stored electronically for statistical analysis. This research was carried out in accordance with the conditions of the Declaration of Helsinki: Recommendations Guiding Physicians in Biomedical Research Involving Human Subjects (http://www.cirp.org/library/ethics/helsinki/) and with the approval of the Police Sports Education Centre.

\section{Subjects}

The sample consisted of 420 healthy male trainees of the Police College in Abu Dhabi (mean age $=20.10 \pm 1.00$ years, mean body weight $=$ $67.61 \pm 9.01 \mathrm{~kg}$, mean body height $173.80 \pm 5.47 \mathrm{~cm}$ ). All trainees were either second, third, or fourth year trainees participating in regular physical training as a part of the academy's physical training program and they had completed a minimum of one year of this physical training program prior to the study.

\section{Testing protocols}

Table 1 shows the organization of the testing sessions used within this investigation with this format used for each of the four testing occasions, June 2016 (end of the school year), September 2016 (beginning of the first term), December 2016 (end of the first term/beginning of the second term), and May 2017 (end of the school year). Each testing session consisted of the test battery displayed, and all the tests were performed in the same order in all the testing sessions.

The trainees were tested in their physical training uniforms, which consisted of T-shirts, shorts, and sport shoes. The testing team consisted of highly trained instructors from the Abu Dhabi Police College. Only repetitions that met the specific protocol for each assessment were counted to ensure the unified testing standards were met. Before each test, trainees were briefed about the specific test criteria and scoring procedures by the instructors. Testing procedures were conducted according to the standards of the Abu Dhabi Police College and Ministry of the Interior. This testing battery consisted of two anthropometric indicators and three physical abilities' parameters. The anthropometric measurements, body weight (BW) and waist circumference (WC), were measured first using a Seca weight scale (Seca 769 digital weight scales), measured to the nearest $\mathrm{kg}$, and a springloaded Gulick measuring tape, measured to the nearest $0.5 \mathrm{~cm}$, at the umbilicus level. The upper body local muscular endurance and abdominal muscular endurance were tested by a commonly used 1-minute push-up test (1-minute PU) and 1-minute sit-up test (1-minute SU) (Hinton, et al., 2017), while the aerobic endurance was assessed using the $2.4 \mathrm{~km}$ run test (RUN).

Table 1. The order of the tests on each occasion

\begin{tabular}{l}
\hline Assessment schedule \\
\hline 1) Body composition \\
- Body weight \\
. Waist circumference \\
5-minute rest \\
2) Physical fitness tests \\
- 1-minute push-ups \\
20-30-minute rest \\
- 1-minute sit-ups \\
20-minute rest \\
- 2.4km run
\end{tabular}

\section{Measurement procedures}

Push-ups. Before the test, trainees had a 5-minute upper body warm-up and two preparatory sets of the self-selected number of PUs using either a traditional or modified (i.e., on knees) PU technique (Suprak, Dawes, \& Stephenson, 2011). Trainees were not allowed to do more than 10 PUs in each of these preparatory sets. Trainees were allowed a maximum of 4-point contact with the ground (i.e. both feet and palms) and were required to maintain a straight and firm body posture (i.e. straight line from toes to the head) throughout the test. The hand width was self-selected based on the trainee's personal preference. However, a hand placement approximately one palm width wider than the shoulder width was advised. The starting position for this test was characterized by the trainees assuming a plank position with their arms fully extended. Trainees were then instructed to bend the elbows and lower their chest toward the ground while maintaining the body posture previously described. A repetition was counted when the elbow joint crossed the position of $90^{\circ}$ and then 
returned to the starting position (Pihlainen, Santtila, Vasankari, Häkkinen, \& Kyröläinen, 2018). Trainees were allowed to rest during the test by raising one hand from the floor to unload and relax the hand. If any part of the body except hands and feet touched the ground, the test was stopped, and the number of correct push-ups performed up until that point was taken as the result of the test. Trainees were organized in as many queues and rows as could be monitored at once. One tester served as a timekeeper, while the others counted repetitions and monitored the correctness of PU technique and form. The same testers were used for each testing day.

Sit-ups. The 1-minute SU test was the second task to be completed. The procedures for performing this test have been outlined in several other studies investigating this population (Dawes, Lindsay, et al., 2017; Dawes, Orr, Kornhauser, Holmes, \& Pope, 2016). The starting position for the trainees was lying on their back, with both feet flat on the ground, knee angles not more than $90^{\circ}$, both shoulder blades on the ground and arms crossed over the chest. Trainees were instructed to flex the trunk and the hips until they were able to touch their knees with the elbows. A repetition was counted when the trainee touched the knees with their elbows and returned to the starting position. While performing a repetition, the palms were not allowed to leave the shoulders. Additionally, swinging and shortening the distance between the elbows and knees was not allowed. Testers were standing on the trainees' feet fixing their feet to the ground.

$2.4 \mathrm{~km}$ run. After the sit-up test, trainees were allowed to rest for 15 minutes. This rest period was followed by a 10-minute lower-body dynamic warm-up routine, led by the instructor consisting of lower-body calisthenics (e.g., low- and high-knees quick steps and short dynamic hops), to prepare participants for the $2.4 \mathrm{~km}$ run. Trainees were instructed to run the distance, on an already practiced running route, in the shortest time possible. Prior to this event, trainees were briefed about the time needed to pass. Before the test, trainees were given a sleeveless green T-shirt with a number on it. The numbers were connected to the student's ID number so the testing team could easily record the results of the test for each trainee. For the time measurement, a Casio stopwatch (Casio HS-70W) was used. All completion times were recorded to the nearest 0.10 second.

\section{Training program}

The planned exercise program included five 60-minute training sessions per week. Every strength development session was composed of a 10-15-minute dynamic warm-up consisting of callisthenic movements, then of three sets of 4-8 body weight exercises focused on movements that required pushing, pulling and lifting, and of 10 minutes of light stretching and relaxation exercises to conclude the training session. The core of strength development sessions consisted of general and specific strength exercises like multi-joint lifts that involved lifting and pushing while in standing or a prone plank position. Every aerobic fitness development class consisted of a warm-up (10 minutes), then of 40 minutes of interval or steady state running, and of a cool down and stretching (15 minutes). Following an ability based training approach (Orr, Ford, \& Stierli, 2016), students were divided into groups according to their physical fitness level, which allowed for the conditioning of students who were below the needed standard. A more detailed description of the weekly training plan is displayed in Table 2.

\section{Semester break period}

The second semester in 2016 ended on May 26 , exactly at the beginning of the holy month of Ramadan, so all students went home for one month of fasting. The fasting month of Ramadan was followed by two more months of a semester break. While on their semester break, the trainees were not provided with any instructions for exercise maintenance, nor were they controlled in any way. Therefore, trainees were not supervised during this period and it was up to each and every individual to maintain their own personal exercise and dietary routine. Studies are indicative but inconclusive, in defining the effects of the holy month of Ramadan fasting on physical performance and body composition (Anis, Leiper, Nizar, Coutts, \& Karim, 2009; Ramadan, 2002). In that regard, the focus of this study is on the effects of 13 weeks of leave, regardless of questionable additional effects of Ramadan fasting.

\section{Statistical analysis}

All results were entered into Microsoft Excel for further analysis. Descriptive statistics for measures of central tendency and dispersion, mean and

Table 2. A sample of the weekly training plan

\begin{tabular}{|c|c|c|c|c|c|c|c|}
\hline Day & Sunday & Monday & Tuesday & Wednesday & Thursday & Friday & Saturday \\
\hline $\begin{array}{l}\text { Physical } \\
\text { ability }\end{array}$ & $\begin{array}{l}\text { Strength } \\
\text { development }\end{array}$ & $\begin{array}{l}\text { Aerobic } \\
\text { fitness }\end{array}$ & $\begin{array}{l}\text { Strength } \\
\text { development }\end{array}$ & $\begin{array}{l}\text { Aerobic } \\
\text { fitness }\end{array}$ & $\begin{array}{l}\text { Strength } \\
\text { development }\end{array}$ & \multirow{2}{*}{$\begin{array}{l}\text { Rest } \\
\text { Students } \\
\text { are out of } \\
\text { the campus }\end{array}$} & Rest \\
\hline $\begin{array}{l}\text { Type of } \\
\text { training }\end{array}$ & $\begin{array}{l}\text { Muscular } \\
\text { endurance }\end{array}$ & $\begin{array}{l}\text { Interval } \\
\text { running }\end{array}$ & $\begin{array}{l}\text { Circuit } \\
\text { training }\end{array}$ & $\begin{array}{l}\text { Continuous } \\
\text { running }\end{array}$ & $\begin{array}{l}\text { Training for muscle } \\
\text { hypertrophy }\end{array}$ & & $\begin{array}{l}\text { Students are } \\
\text { out of the } \\
\text { campus }\end{array}$ \\
\hline
\end{tabular}


$\mathrm{SD}$, were calculated in Microsoft Excel. To investigate the effects of training and the leave period on physical fitness levels, a repeated measure analysis of variance (two-way ANOVA) was employed with the significance level set at $p<.05$. To define the differences between the results of different testing sessions, the Bonferroni post-hoc test was applied. The statistical software package SPSS (IBM, SPSS Statistics 20) was used for the analyses.

\section{Results}

Table 3 shows the mean and standard deviation for each variable tested on each testing occasion. Generally, ANOVA established significant effects for both investigated periods on the followed variables.

The analysis found that the measured anthropometric parameters significantly increased over the semester leave period: BW increased by $1.27 \pm 3.11$ $\mathrm{kg}$, while WC increased by $2.36 \pm 3.68 \mathrm{~cm}$ (Figure 1). However, once the students started a new school year and participated in the physical activity curriculum from September to December, BW and WC returned almost to the initial level. BW decreased by $1.03 \pm 2.25 \mathrm{~kg}$, which was followed with an average decrease of $1.86 \pm 3.16 \mathrm{~cm}$ for WC (Figure 1). After the students reached a certain level of BW, there was no significant change through the semesters with the average difference being $0.40 \pm 3.97 \mathrm{~kg}$. Conversely, WC significantly increased by $0.79 \pm 4$ $\mathrm{cm}$ (Figure 1).

All the investigated physical abilities changed significantly due to the effects of the semester break and the subsequent physical training (Figure 2). As shown in Figure 2, the PU and SU performance decreased significantly following the semester break by means of $1.33 \pm 6.07$ and $3.44 \pm 5.88$ repetitions, respectively. After the trainees' participation in physical activity classes from September to December, both abilities significantly increased by means of $2.94 \pm 6.64$ and $2.90 \pm 5.64$ repetitions, respectively. Furthermore, as the physical training continued from December to May, the improvement in the PU and SU performance was still significant, with PU and SU increasing by means of $1.00 \pm 6.91$ and $2.61 \pm 6.28$ repetitions, respectively.
When assessing the differences in cardiovascular fitness, or running performance, the results showed the similar effects of training on the running performance as in the PU and SU. Immediately after the semester break (June to September), the time taken to complete the $2.4 \mathrm{~km}$ distance increased by a mean of $29.58 \pm 31.71 \mathrm{~s}$., while after the first semester, lasting from September until December, run time decreased by a mean of $33.52 \pm 30.65 \mathrm{~s}$. From December to May, times increased slightly, by a mean of $8.71 \pm 29.28 \mathrm{~s}$, although this was not significant.
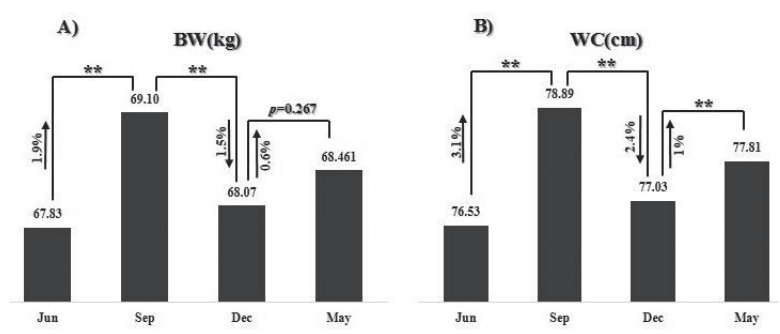

Figure 1. Absolute and relative effects of the semester break and training on $B W(A)$ and $W C(B)$, with the significance level of $p<.01$ represented as $* *$.
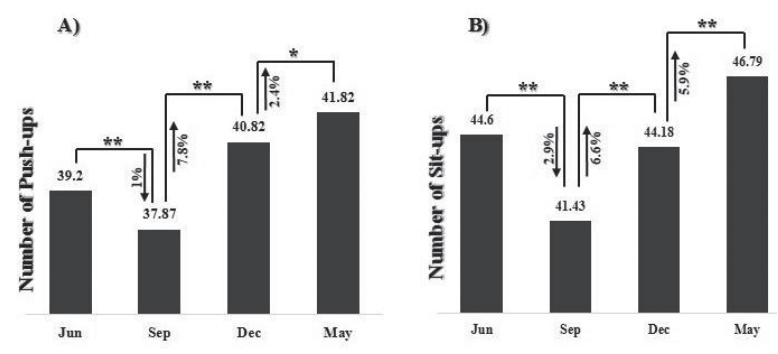

Figure 2. Absolute and relative effects of detraining and training on $P U(A)$ and $S U$ (B) performance, with the significance level of $p<.01$ represented as ** and $p<.05$ as *.

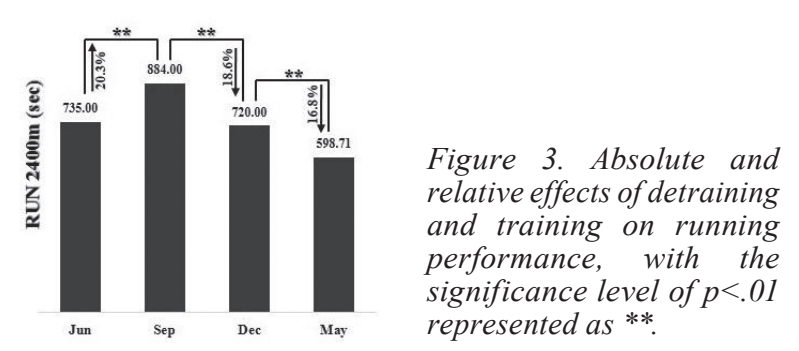

Table 3. Descriptive statistics for the investigated variables with the ANOVA results on general level

\begin{tabular}{lcccccc}
\hline & June & September & December & May & & \\
Variables & $\mathbf{2 0 1 6}$ & $\mathbf{2 0 1 6}$ & $\mathbf{2 0 1 6}$ & $\mathbf{2 0 1 7}$ & $\mathrm{F}$ & $\mathrm{p}$ \\
& Mean \pm SD & Mean \pm SD & Mean \pm SD & Mean \pm SD & & \\
\hline BW (kg) & $67.83 \pm 9.01$ & $69.10 \pm 9.55$ & $68.07 \pm 9.07$ & $68.46 \pm 9.04$ & 5.657 & .004 \\
WC (cm) & $76.32 \pm 6.46$ & $78.56 \pm 7.12$ & $76.86 \pm 6.42$ & $77.43 \pm 6.76$ & 29.256 & $<.001$ \\
PU (rep.) & $39.42 \pm 7.01$ & $38.10 \pm 7.09$ & $41.04 \pm 7.60$ & $42.06 \pm 6.82$ & 22.301 & $<.001$ \\
SU (rep.) & $44.96 \pm 6.69$ & $41.52 \pm 5.47$ & $44.42 \pm 6.93$ & $47.02 \pm 6.71$ & 57.223 & $<.001$ \\
RUN (s) & $593.94 \pm 32.61$ & $623.51 \pm 33.98$ & $590.00 \pm 33.12$ & $598.71 \pm 32.52$ & 82.175 & $<.001$ \\
\hline
\end{tabular}




\section{Discussion and conclusion}

The main findings of this study indicate that once the trainees returned to college and went through the first and second semester of the physical training program, their BW and WC significantly decreased, while their muscular endurance and cardio-respiratory fitness significantly improved. Conversely, once the trainees finished the school year and left college for the semester break, their BW and WC significantly increased. Furthermore, these changes also corresponded to significant reductions in muscular endurance and cardio-respiratory fitness. Thus, both tested hypotheses have been shown to be true. According to the authors' knowledge, there are no current studies that have investigated the effects of detraining over the semester break in this population. Thus, this research helps fill a significant gap in the current literature related to this topic. This information can be used by police colleges to help reduce the deleterious effects of detraining over the summer break time period. Furthermore, and most notably, the findings of this study present some insights into what may occur when trainees no longer receive further formal physical training and may add new insights into why police officers lose fitness when they are no longer at a training academy (Orr, et al., 2017).

Numerous investigations have shown that participation in a structured physical training program has a positive impact on health, fitness and performance within tactical populations. Malavolti et al. (2008) investigated the effects of rigorous physical training for Navy forces on body composition when performing a 5-day per week physical training program performed for a total of 40 hours per week. After the first phase, BW decreased by $2.2 \%$, which was the result of the loss of fat mass and fat-free mass, and after the second phase, BW increased significantly on account of the fat-free mass. In contrast, two recent studies conducted with military recruits did not show significant changes in BW after eight and 12 weeks of physical training. The most probable cause lies in the significant decrease in percentage of fat mass and a decrease in WC, while lean mass significantly increased (Campos, Campos, Bezerra, \& Pellegrinotti, 2017; Vantarakis, et al., 2017). Similarly, Malavolti et al. (2008) reported a significant decrease in fat-free mass after rigorous ground and sea Navy physical training, which was followed by a significant increase in fat-free mass once the training load was decreased due to time spent in amphibious training.

This study showed similar trends as the study of Malavolti et al. (2008) as, from September to December, BW and WC decreased significantly and then, until May, BW slightly increased $(p=.267)$ by $0.39 \pm 3.98 \mathrm{~kg}$, while WC increased more significantly $(\mathrm{p}<.001)$ by $0.79 \pm 4 \mathrm{~cm}$. Note that trainees in this study started the training program in September, after the semester break, which was shown to have a negative effect on all the investigated variables. This could be an additional reason why BW and WC significantly decreased from September until December but then slightly changed from December to May. Unfortunately, lean, fat-free or muscle mass, were not measured in this study and, as such, it can only be hypothesized that these changes occurred due to an increase in fat mass, but also fat-free mass (Campos, et al., 2017; Malavolti, et al., 2008; Vantarakis, et al., 2017).

The results of the Bonferroni post-hoc analysis (Figures 2 and 3) showed that statistically significant differences occurred in all the tested physical abilities on both testing occasions (December and May), which suggested that the applied physical training sessions significantly affected trainees' performance on the abilities tested. These findings are in agreement with previous research that has shown various physical training programs to have a positive effect on physical abilities and performance of police and military personnel (Campos, et al., 2017; Cocke, Dawes, \& Orr, 2016; Crawley, et al., 2016; Dimitrijević, et al., 2014; Vantarakis, et al., 2017). Significant improvements in the number of performed push-ups and sit-ups in our study are similar to those found in studies that investigated the effects of the training programs on Police Academy and Navy Trainees and Military recruits (Campos, et al., 2017; Cocke, et al., 2016; Crawley, et al., 2016; Vantarakis, et al., 2017). Furthermore, these researchers also observed a significant decrease in running time, which is in line with the significant improvements in the number of finished running shuttles as well as in $\mathrm{VO}_{2}$ max seen in other studies (Campos, et al., 2017; Cocke, et al., 2016; Crawley, et al., 2016).

Opposed to the findings of this research, Vantarakis et al. (2017) found significant improvements in push-ups, sit-ups, 30m-sprint and hand grip strength; however, no improvement in absolute and relative $\mathrm{VO}_{2}$ max were shown after two months of training. Various explanations for these differences could exist and include the utilization of a linear periodized resistance training method with an insufficient amount of aerobic training performed to affect the significant improvements in oxygen consumption or potential differences in the nature of the aerobic training. Furthermore, the number of training sessions may provide a potential explanation. Dimitrijević et al. (2014) compared the effects of three different special physical education curricula that were regularly applied at the Academy for Criminalistics and Police Studies in Serbia. Even though the aim of the special physical education program was the same, authors found that curricula with the highest number of classes (272 per year) had a stronger significant positive effect on 
long jump, trunk muscular endurance and $\mathrm{VO}_{2} \max$ than the curricula with fewer classes (250 and 180 classes). Thus, if one of the goals of the physical training program is to develop cardio-respiratory fitness, the intensity and frequency of training should be considered and monitored carefully.

The results of this study suggest that after three months of no formal physical training, a detraining effect occurred with the police trainees significantly increasing in BW and WC. Similar results have been seen in athletes as a result of a detraining period. For instance, when investigating female swimmers, Ormsbee and Arciero (2012) found that after five weeks of detraining, BW significantly increased by $1.3 \%$, body fat mass by $12.2 \%$, body fat percentage by $2 \%$, and WC by $1.5 \%$. When three different training programs (aerobic, resistance and combined) were applied, Theodorou et al. (2016) found that BW and BMI significantly increased after one, two and three months of detraining after the aerobic and combined type of training. These researchers also discovered that body fat percentage significantly increased after one month of detraining in all the three applied training programs. In a study conducted by Pihlainen et al. (2018) with military personnel it was found that during six months of international crisis management, where physical training was limited, there was a significant increase in body fat mass and skeletal muscle mass $(4.27 \%$ and $0.51 \%$, respectively) among administrative officers in the second half of the study. Conversely, infantry units significantly increased skeletal muscle mass by $0.75 \%$ and BW by $0.63 \%$, with no significant changes in these variables during the second half of the study. The authors reported that the physical activity level was surprisingly low with less than 10,000 steps per day in both groups, which is less than population-wide activity guidelines. The trend of decreased levels of physical activity during the semester break most likely explains the significant increase in BW and WC observed in this investigation.

Numerous studies have investigated the effects of detraining on physical abilities and performance, but none have investigated these effects within a police population (Fleck, 1994; Liguori, Krebsbach, \& Schuna Jr., 2012; Ormsbee \& Arciero, 2012; Theodorou, et al., 2016). A decrease in relativised maximal oxygen uptake has been reported in male and female army reserve officers $(-3.60 \%$ in males and $-7.5 \%$ in females) after three months without mandatory physical training (Liguori, et al., 2012). Similarly, Ormsbee and Arciero (2012) reported a decrease of $7.7 \%$ in $\mathrm{VO}_{2} \max$ and a $7 \%$ decrease in resting metabolic rate after 35 days of detraining in Division III collegiate swimmers. Theodorou et al. (2016) found a significant decrease in knee extensors and flexor torque after one and two months of detraining, depending on the used training program. In the aerobic group, a significant decrement occurred in extensor torque only after the first month of detraining ( $2 \%$ first month vs $1.6 \%$ second month), while in the resistance and combined group a significant decrement occurred after both months of detraining $-0.98 \%$ vs $8.17 \%$ in the resistance group and $1.96 \%$ vs $6.88 \%$ in the combined group. Alternatively, only the resistance and the combined group showed a significant decrement in knee flexors torque after one and two months of detraining $(0.28 \%$ vs $7.48 \%$ in the resistance and $1.22 \%$ vs $4.55 \%$ in the combined group), while there were no significant changes in the aerobic group (Theodorou, et al., 2016). The above-mentioned studies suggest that even relatively short periods without proper levels of physical training may have a significant negative effect on body composition, aerobic fitness and strength. The results of this study showed a similar trend among police trainees.

To the authors' knowledge this is the only study that has specifically investigated the effects of a structured training program and a semester break on both anthropometric parameters and physical abilities in police trainees. As such, the findings of this study suggest that a planned and supervised prolonged training, implemented through physical education classes can improve the anthropometric and fitness variables in police trainees, while a semester break without a planned and supervised exercise program may lead to an increase in body weight and waist circumference. While the positive alterations in body composition may improve the trainees overall physical appearance, which is important to the public perception of an officer being "fit for duty", the impact of non-formal physical training during the semester break may serve as a warning to the impacts of a loss of formal training once police trainees leave the academy. Future research should investigate means of educating new police trainees on the means of maintaining their health and fitness during periods without formal physical training. This may present a future considerations for educating officers on importance of maintaining their fitness once they finish with formal training.

\section{Practical implication}

The presented study clearly indicates that regular physical activity positively affects the physical performance and body composition of police trainees. These findings suggest that engaging in a planned exercise programs should be applied in tactical populations to optimize and maintain their health and occupational performance. Furthermore, strategies for maintaining physical fitness during leave periods should be developed in order to minimize the negative impact of planned leave periods and potential detraining among police trainees. 


\section{References}

American College of Sports Medicine. (2013). ACSM's health-related physical fitness assessment manual. Lippincott Williams \& Wilkins.

Anderson, G.S., Plecas, D., \& Segger, T. (2001). Police officer physical ability testing - Re-validating a selection criterion. Policing, 24(1), 8-31.

Anderson, G.S., \& Plecas, D.B. (2000). Predicting shooting scores from physical performance data. Policing, 23(4), 525-537.

Anis, C., Leiper, J.B., Nizar, S., Coutts, A.J., \& Karim, C. (2009). Effects of Ramadan intermittent fasting on sports performance and training: A review. International Journal of Sports Physiology and Performance, 4(4), 419-434.

Boyce, R., Jones, G., Llyod, C., \& Boone, E. (2008). A longitudinal observation of police: Body composition changes over 12 years with gender and race comparisons. Journal of Exercise Physiology Online, 11(6), 1-13.

Campos, L.C., Campos, F.A., Bezerra, T.A., \& Pellegrinotti, Í.L. (2017). Effects of 12 weeks of physical training on body composition and physical fitness in military recruits. International Journal of Exercise Science, $10(4), 560$.

Cocke, C., Dawes, J.J., \& Orr, R.M. (2016). The use of 2 conditioning programs and the fitness characteristics of police academy cadets. Journal of Athletic Training, 51(11), 887-896. doi: 10.4085/1062-6050-51.8.06

Crawley, A.A., Sherman, R.A., Crawley, W.R., \& Cosio-Lima, L.M. (2016). Physical fitness of police academy cadets: Baseline characteristics and changes during a 16-week academy. Journal of Strength and Conditioning Research, 30(5), 1416-1424. doi: 10.1519/JSC.0000000000001229

Dawes, J.J., Lindsay, K., Bero, J., Elder, C., Kornhauser, C., \& Holmes, R. (2017). Physical fitness characteristics of high vs. low performers on an occupationally specific physical agility test for patrol officers. Journal of Strength and Conditioning Research, 31(10), 2808-2815.

Dawes, J.J., Orr, R.M., Elder, C., \& Rockwell, C. (2014). Association between body fatness and measures of muscular endurance among part-time SWAT officers. Journal of Australian Strength and Conditioning, 22(4), 33-37.

Dawes, J.J., Orr, R.M., Flores, R.R., Lockie, R.G., Kornhauser, C., \& Holmes, R. (2017). A physical fitness profile of state highway patrol officers by gender and age. Annals of Occupational and Environmental Medicine, 29(1), 16. doi: 10.1186/s40557-017-0173-0

Dawes, J.J., Orr, R.M., Kornhauser, C., Holmes, R., \& Pope, R. (2016). Differences in initial fitness scores between highway patrol cadets who successfully complete or fail to complete a 27-week training academy. Journal of Australian Strength and Conditioning, 24(6), 76-77.

Dimitrijević, R., Koropanovski, N., Dopsaj, M., Vučković, G., \& Janković, R. (2014). The influence of different physical education programs on police students' physical abilities. Policing, 37(4), 794-808.

Fleck, S.J. (1994). Detraining: Its effects on endurance and strength. Strength and Conditioning Journal, 16(1), $22-28$.

Gu, M.J.K., Charles, L.E., Burchfiel, C.M., Fekedulegn, D., Sarkisian, M.K., Andrew, M.E., . ., \& Violanti, J.M. (2012). Long work hours and adiposity among police officers in a US Northeast City. Journal of Occupational and Environmental Medicine, 54(11), 1374.

Hauschild, V.D., DeGroot, D.W., Hall, S.M., Grier, T.L., Deaver, K.D., Hauret, K.G., \& Jones, B.H. (2017). Fitness tests and occupational tasks of military interest: A systematic review of correlations. BMJ Occupational and Environmental Medicine, 74(2), 144-153. doi: oemed-2016-103684.

Hinton, B., Stierli, M., \& Orr, R.M. (2017). Physiological issues related to law enforcement personnel. In B. Alvar, K. Sell \& P.A. Deuster (Eds.), NSCA's essentials of tactical strength and conditioning (pp. 577-604). Champaign, IL: Human Kinetics.

Lagestad, P. (2012). Physical skills and work performance in policing. International Journal of Police Science and Management, 14(1), 58-70.

Lagestad, P., \& Van den Tillaar, R. (2014a). A comparison of training and physical performance of police students at the start and the end of three-year police education. Journal of Strength and Conditioning Research, 28(5), 1394-1400.

Lagestad, P., \& Van Den Tillaar, R. (2014b). Longitudinal changes in the physical activity patterns of police officers. International Journal of Police Science and Management, 16(1), 76-86.

Liguori, G., Krebsbach, K., \& Schuna Jr., J. (2012). Decreases in maximal oxygen uptake among army reserve officers' training corps cadets following three months without mandatory physical training. International Journal of Exercise Science, 5(4), 354.

Lonsway, K.A. (2003). Tearing down the wall: Problems with consistency, validity, and adverse impact of physical agility testing in police selection. Police Quarterly, 6(3), 237-277.

Malavolti, M., Battistini, N.C., Dugoni, M., Bagni, B., Bagni, I., \& Pietrobelli, A. (2008). Effect of intense military training on body composition. Journal of Strength and Conditioning Research, 22(2), 503-508.

Ormsbee, M.J., \& Arciero, P.J. (2012). Detraining increases body fat and weight and decreases VO2peak and metabolic rate. Journal of Strength and Conditioning Research, 26(8), 2087-2095.

Orr, R.M., Dawes, J.J., Pope, R., \& Terry, J. (2018). Assessing differences in anthropometric and fitness characteristics between police academy cadets and incumbent officers. Journal of Strength and Conditioning Research, 32(9), 2632-2641. doi: 10.1519/JSC.0000000000002328 
Orr, R.M., Ford, K., \& Stierli, M. (2016). Implementation of an ability based training program in police force recruits. Journal of Strength and Conditioning Research, 30(10), 2781-2787. doi:doi: 10.1519/JSC.0000000000000898

Pihlainen, K., Santtila, M., Vasankari, T., Häkkinen, K., \& Kyröläinen, H. (2018). Evaluation of occupational physical load during 6-month international crisis management operation. International Journal of Occupational Medicine and Environmental Health, 31(2), 185-197.

Ramadan, J. (2002). Does fasting during Ramadan alter body composition, blood constituents and physical performance? Medical Principles and Practice, 11(Suppl. 2), 41-46.

Shusko, M., Benedetti, L., Korre, M., Eshleman, E., Farioli, A., Christophi, C., \& Kales, S. (2017). Recruit fitness as a predictor of police academy graduation. Occupational Medicine, 67(7), 555-561.

Sörensen, L., Smolander, J., Louhevaara, V., Korhonen, O., \& Oja, P. (2000). Physical activity, fitness and body composition of Finnish police officers: A 15-year follow-up study. Occupational Medicine, 50(1), 3-10.

Stojković, M., Čvorović, A., Jeknić, V., \& Kukić, F. (2017). Influence of two-month training program on anthropometry and VO2max in recreational athletes. International Journal of Physical Education, Fitness and Sports, 19(24), 19-24.

Suprak, D.N., Dawes, J., \& Stephenson, M.D. (2011). The effect of position on the percentage of body mass supported during traditional and modified push-up variants. Journal of Strength and Conditioning Research, 25(2), $497-503$.

Theodorou, A.A., Panayiotou, G., Volaklis, K.A., Douda, H.T., Paschalis, V., Nikolaidis, M.G., ..., \& Papadopoulos, I. (2016). Aerobic, resistance and combined training and detraining on body composition, muscle strength, lipid profile and inflammation in coronary artery disease patients. Research in Sports Medicine, 24(3), 171-184.

Vantarakis, A., Chatzinikolaou, A., Avloniti, A., Vezos, N., Douroudos, I.I., Draganidis, D., ..., \& Fatouros, I.G. (2017). A 2-month linear periodized resistance exercise training improved musculoskeletal fitness and specific conditioning of navy cadets. Journal of Strength and Conditioning Research, 31(5), 1362-1370.

Violanti, J.M., Burchfiel, C.M., Hartley, T.A., Mnatsakanova, A., Fekedulegn, D., Andrew, M.E., . .., \& Vila, B.J. (2009). Atypical work hours and metabolic syndrome among police officers. Archives of Environmental and Occupational Health, 64(3), 194-201.

Submitted: April, 1, 2018

Accepted: January 18, 2019

Published Online First: October, 15, 2019

Correspondence to:

Assoc. Prof. Robin Orr, PhD, MPhty, BFET

Tactical Research Unit, Bond University, Gold Coast, QLD, Australia

Phone: +61 468646027

Email: rorr@bond.edu.au 